\title{
Quantification of Microbial Communities in Hydrothermal Vent Habitats of the Southern Mariana Trough and the Mid-Okinawa Trough
}

\author{
Katsunori Yanagawa, Jun-ichiro Ishibashi, Takao Arai, Tetsuro Urabe, and \\ Michinari Sunamura
}

\begin{abstract}
The structure of microbial populations near chemosynthetic faunal communities of two geographically and geologically distinct deep-sea hydrothermal vent fields were quantitatively evaluated using catalyzed reporter deposition-fluorescence in situ hybridization (CARD-FISH). The hydrothermal vent of the Southern Mariana Trough (SMT) was dominated by colonization of gastropods in the low-temperature diffuse hydrothermal fluid, whereas macrofauna in mixing zones of the Mid-Okinawa Trough (MOT) consisted of polychaetes, galatheid crabs, and bivalves. A quantitative comparison revealed that the microbial community of the SMT hydrothermal vent field is significantly different from that of the MOT and is strongly influenced by mixing conditions between reduced hydrothermal fluid and oxygenated seawater. In particular, a high proportion of Epsilonproteobacteria was found in the SMT hydrothermal fluid, which is composed of approximately $88 \%$ seawater. In contrast, sulfur oxidizers in Gammaproteobacteria were most abundant near vent fauna habitats in the MOT. Our results suggest that the SMT hydrothermal environment is distinct from that of the MOT and affects the community structure of macrofauna and microbial flora.
\end{abstract}

\section{Keywords}

Deep-sea hydrothermal vent • Fluorescence in situ hybridization (FISH) • Hydrothermal mixing zone $\bullet$ Quantitative microbial community analysis

K. Yanagawa $(\bowtie)$

Department of Earth and Planetary Science, University of Tokyo,

7-3-1 Hongo, Bunkyo-ku, Tokyo 113-0033, Japan

Subsurface Geobiology Advanced Research (SUGAR) Project, Japan Agency for Marine-Earth Science and Technology

(JAMSTEC), Yokosuka 237-0061, Japan

e-mail: kyanagawa@jamstec.go.jp

J.-i. Ishibashi

Department of Earth and Planetary Sciences, Faculty of Science,

Kyushu University, Higashi-ku, Fukuoka 812-8581, Japan

T. Arai

Department of Applied Biological Science, Tokyo University

of Science, 2641 Yamazaki, Noda, Chiba 278-851, Japan

T. Urabe • M. Sunamura

Department of Earth and Planetary Science, University of Tokyo,

7-3-1 Hongo, Bunkyo-ku, Tokyo 113-0033, Japan

\subsection{Introduction}

In a deep-sea hydrothermal environment, mixing between hot, reduced hydrothermal vent fluids and cold, oxygenated ambient seawater forms a steep physical and chemical gradient. Vent-derived electron donors and seawater-derived electron acceptors are a source of energy for chemolithotrophic growth of prokaryotes, both of free-living and symbiotic forms. Consequently, these microorganisms play a fundamental role in sustaining primary production in hydrothermal ecosystems, supporting the growth of heterotrophic microbial flora and fauna, and maintaining the diversity and population density, thus creating an oasis for life in the deep-sea "desert" (Corliss et al. 1979; Karl 1995).

The geochemical profiles of hydrothermal fluids fluctuate temporally and spatially, due to the complex inorganic 
Table 6.1 CARD-FISH probes used in this study

\begin{tabular}{|c|c|c|c|c|c|c|}
\hline Probe & Specificity & Sequence $\left(5^{\prime}-3^{\prime}\right)^{\mathrm{a}}$ & Target site ${ }^{\mathrm{b}}$ & $\begin{array}{l}\text { FA ( } \%, \text { vol/ } \\
\text { vol })^{\mathrm{c}}\end{array}$ & $\begin{array}{l}\mathrm{NaCl} \\
(\mathrm{mM})^{\mathrm{d}}\end{array}$ & References \\
\hline EUB338 I & Bacteria & GCTGCCTCCCGTAGGAGT & $16 \mathrm{~S},(338-355)$ & 55 & 3 & Amann et al. (1995) \\
\hline $\begin{array}{l}\text { EUB338 } \\
\text { II }\end{array}$ & Planctomycetales & GCAGCCACCCGTAGGTGT & $16 \mathrm{~S},(338-355)$ & 55 & 3 & Daims et al. (1999) \\
\hline $\begin{array}{l}\text { EUB338 } \\
\text { III }\end{array}$ & Verrucomicrobiales & GCTGCCACCCGTAGGTGT & $16 \mathrm{~S},(338-355)$ & 55 & 3 & Daims et al. (1999) \\
\hline ARCH915 & Archaea & GTGCTCCCCCGCCAATTCCT & $16 \mathrm{~S},(915-934)$ & 60 & 0 & Amann et al. (1995) \\
\hline ALF968 & Alphaproteobacteria & GGTAAGGTTCTGCGCGTT & $16 \mathrm{~S},(968-985)$ & 30 & 3 & Neef (1997) \\
\hline BET42a & Betaproteobacteria & GCCTTCCCACTTCGTTT & $\begin{array}{l}23 S, \\
(1027-1043)\end{array}$ & 55 & 3 & Manz et al. (1992) \\
\hline GAM42a & Gammaproteobacteria & GCCTTCCCACATCGTTT & $\begin{array}{l}23 S, \\
(1027-1043)\end{array}$ & 55 & 3 & Manz et al. (1992) \\
\hline DEL495 & Deltaproteobacteria & ARTTAGCCGGYGCTTCCT & $16 \mathrm{~S},(495-512)$ & 55 & 3 & Loy et al. (2002) \\
\hline EP402 & Epsilonproteobacteria & GAAAKGYGTCATCCTCCACG & $16 \mathrm{~S},(402-423)$ & 35 & 42 & Takai et al. (2004) \\
\hline CF319a & $\begin{array}{l}\text { Cytophaga- } \\
\text { Flavobacterium }\end{array}$ & TGGTCCGTRTCTCAGTAC & $16 \mathrm{~S},(319-336)$ & 55 & 3 & Manz et al. (1996) \\
\hline $\begin{array}{l}\text { SUP05- } \\
187\end{array}$ & SUP05 & GGGCTCСTTTTCTCСATA & $16 \mathrm{~S},(787-205)$ & 55 & 3 & $\begin{array}{l}\text { Sunamura et al. } \\
(2004)\end{array}$ \\
\hline
\end{tabular}

${ }^{\mathrm{a}} \mathrm{M}=\mathrm{A}$ or $\mathrm{C}, \mathrm{R}=\mathrm{G}$ or $\mathrm{A}, \mathrm{Y}=\mathrm{C}$ or $\mathrm{T}, \mathrm{W}=\mathrm{A}$ or $\mathrm{T}, \mathrm{K}=\mathrm{G}$ or $\mathrm{T}$

${ }^{\mathrm{b}}$ Position in the $16 \mathrm{~S}$ or $23 \mathrm{~S}$ rRNA of E. coli

${ }^{\mathrm{c}}$ Formamide concentrations in the hybridization buffer

${ }^{d} \mathrm{NaCl}$ concentrations in the wash buffer

reactions in the fluid conduit (Le Bris et al. 2006; Rogers et al. 2007; Zielinski et al. 2011). The fluctuation of geochemical composition in hydrothermal mixing zones may have a significant impact on the rate of microbial growth and metabolic activity, biogeochemical reactions, and the dominant microbial population. In particular, reduced compounds such as $\mathrm{H}_{2}, \mathrm{CH}_{4}, \mathrm{HS}^{-}$, and $\mathrm{Fe}^{2+}$ are not only essential energy sources for chemolithotrophs but also factors that control the composition and density of the microbial community. Previous studies have investigated habitat components, for example, the boundary zone (interface) between hydrothermal fluid and ambient seawater, including low-temperature diffusive flow (Holden et al. 1998; Huber et al. 2002, 2003; Perner et al. 2007), chimney structures (Schrenk et al. 2003; Takai et al. 2001), and hydrothermal sediments (Nunoura et al. 2010; Teske et al. 2002; Yanagawa et al. 2013). These studies demonstrated the prevalence of Gammaproteobacteria, Deltaproteobacteria, Epsilonproteobacteria, Bacteroidetes, Firmicutes, and various candidate divisions in the hydrothermal system. Due to fluctuations in the environmental conditions, microbial communities in hydrothermally influenced regions exhibit variability on various spatial and temporal scales, including large-scale intra- and inter-field variability (Flores et al. 2012; Huber et al. 2010; Nunoura and Takai 2009), short-term temporal and spatial variability (Perner et al. 2009, 2013), and spatial variability on a small scale of a few centimeters to meters (Nakagawa et al. 2005; Takai et al. 2004). However, most studies focused on the variability of specific microbial populations in the zone adjacent to hydrothermal vents. To better understand microbial population dynamics and their relation to hydrothermal environments in terms of chemistry and temperature, a quantitative approach to whole microbial members is necessary.

Despite the data accumulation of microbial diversity based on 16S rRNA sequencing, relatively few studies have conducted a quantitative analysis of microbial community composition in hydrothermal mixing zones. Fluorescence in situ hybridization (FISH) is one of the most reliable methods for quantifying microbial populations and can provide important information regarding the spatial distribution, diversity, abundance, and composition of microbial communities in the environment. Here, we describe the microbial composition of regions where reduced hydrothermal fluid and oxygenated seawater mix using catalyzed reporter deposition FISH (CARD-FISH). The hydrothermal fluid samples were collected around the Southern Mariana Trough (SMT) and the Mid-Okinawa Trough (MOT) in the western Pacific, two geographically and geologically distinct hydrothermal vents. The zonation of hydrothermal vent fauna (gastropods, polychaetes, galatheid crabs, and mussels) was used as a potential environmental indicator of physical and chemical gradients formed by the mixing of reduced hydrothermal fluid and oxygenated seawater. CARD-FISH, using nine oligonucleotide probes, identified several major phylogenetic groups including Bacteria, Archaea, Alphaproteobacteria, Betaproteobacteria, Gammaproteobacteria, Deltaproteobacteria, Epsilonproteobacteria, the Cytophaga-Flavobacterium cluster, and the SUP05 group of gammaproteobacterial sulfur oxidizers (Table 6.1) as components of the microbial community 
associated with hydrothermal fluids and nearby vent fauna. These results increase our understanding of mesoscale (tens of centimeters to meters) spatial variation in microbial populations and long-term (year-scale) microbial dynamics.

\subsection{Materials and Methods}

\subsubsection{Sampling Sites and Sample Collection}

The hydrothermally influenced fluids were collected around the shimmering water that emerged through the gastropod patches (Snail site: $12^{\circ} 57.190^{\prime} \mathrm{N}, 143^{\circ} 37.165^{\prime} \mathrm{E}$, water depth: $2,850 \mathrm{~m}$ ) at the center of the spreading back-arc basin of the SMT (for a detailed description, see Toki et al. Chap. 45), and around the hydrothermal mixing zones within the large sulfide mound (North Big Chimney: $27^{\circ} 47.451^{\prime} \mathrm{N}$, $126^{\circ} 53.805^{\prime} \mathrm{E}$, water depth: $982 \mathrm{~m}$ ) in the Iheya North Knoll hydrothermal field of the MOT (see Kawagucci Chap. 30). From the SMT hydrothermal field, 11 different shimmering fluids and 2 ambient seawater samples were collected during the YK03-09 cruise (14 Oct to 14 Nov 2003 ) and the YK05-09 cruise (24 Jul to 10 Aug 2005) of the R/V Yokosuka using the manned submersible Shinkai 6500 and during the TN167A cruise (15-27 Mar 2004) of the $\mathrm{R} / \mathrm{V}$ Thomas G. Thompson using the remotely operated vehicle (ROV) ROPOS (Table 6.2). The Snail site is located on a mound of pillow lava, and low-temperature diffuse fluids emanate from hydrothermal vents and are densely inhabited with the gastropod Alviniconcha hessleri around Marker \#21 and Marker \#24. A low-temperature hydrothermal vent site is also located to the south of the Snail site, where a microbial mat-like structure was observed in the vicinity of Marker \#78. From the MOT, 3 hydrothermal fluids and 2 seawater samples were obtained during the NT05-03 cruise (14-20 Apr 2003) of the R/V Natsushima using the ROV Hyper-Dolphin (Table 6.2). Hydrothermal vents are surrounded by habitat zones of polychaetes, galatheid crabs (Shinkaia crosnieri), and bivalves (genus Bathymodiolus), in order of increasing distance from the vent, which may be due to the optimal hydrothermal mixing required to support the growth of these species.

The hydrothermal fluid samples were taken from each SMT and MOT sampling area using a bag sampling system, a rotary clean seawater sampling system (Kato et al. 2009), and a Niskin bottle (Table 6.2). The collected samples were immediately fixed for $6 \mathrm{~h}$ with $3.7 \%$ neutralized formalin and stored at $-80{ }^{\circ} \mathrm{C}$ for analysis onshore.

\subsubsection{Chemical Characteristics of Hydrothermal Fluids}

The onboard analyses, including potentiometric techniques, colorimetric methods, titration, and liquid chromatography were performed as described by Gieskes et al. (1991). The $\mathrm{pH}$ at room temperature was determined using a $\mathrm{pH}$ meter with a combined glass electrode (IWAKI, IW055-BNC). The $\mathrm{pH}$ meter was calibrated daily using JSCS buffer solutions $(\mathrm{pH}=6.865$ and 4.010$)$. Alkalinity was determined by titration with hydrochloric acid. The endpoint was calculated by Gran plot, using a pH meter (Corning, M-250) as a potentiometer. The calibration was verified by analyzing IAPSO standard seawater (with a known alkalinity of $2.45 \mathrm{mM}$ ), and the analytical precision was estimated to be within $3 \%$. The concentrations of dissolved silica, ammonium ions, and hydrogen sulfide were measured with a colorimeter by classical methods (Hach, DR2010) using molybdenum blue, indo-phenol and methylene blue, respectively. The analytical precision was generally estimated to be within $3 \%$ for the seawater analysis.

The nitrate concentration was determined onboard using a liquid chromatograph (Shimadzu, LC10AI) with a UV detector $(\lambda=220 \mathrm{~nm}$, Shimadzu, SPD10AVP) following a modified protocol (Maruo et al. 2006). To eliminate interference from major anions such as $\mathrm{Cl}^{-}$and $\mathrm{SO}_{4}{ }^{2-}$, a highcapacity anion exchange column (Tosoh, TSK gel-SAX, $4.6 \times 50 \mathrm{~mm}$ ) was used with a $1 \mathrm{M}$ sodium chloride eluent at a flow rate of $0.8 \mathrm{ml} / \mathrm{min}$. Chloride concentration was determined by Mohr's method, using silver nitrate solution as the titrant and chromate solution as the indicator. Sulfate concentration was determined in the onshore laboratory using an ion chromatograph (Dionex DX-100) after diluting the samples to a ratio of 1:300. The concentrations of major and minor cations ( $\mathrm{Na}, \mathrm{K}, \mathrm{Ca}, \mathrm{Mg}, \mathrm{Sr}, \mathrm{B}, \mathrm{Mn}$, and $\mathrm{Fe}$ ) were determined in the onshore laboratory using a flame spectrophotometer (Shimadzu AA-680) and inductively coupled plasma atomic emission spectrometry (ICP-AES; Seiko, SPS 1200AR) after diluting the samples adequately. The precision of these instrumental analyses was estimated to be within $5 \%$ based on repeated analysis of a working standard.

All of the geochemical data from the SMT hydrothermal field are shown by Toki et al. (Chap. 45).

\subsubsection{Catalyzed Reporter Deposition- Fluorescence In Situ Hybridization}

The fixed samples were thawed and filtered through $0.2-\mu \mathrm{m}-$ pore-size polycarbonate filters to isolate microbial cells. 
总 

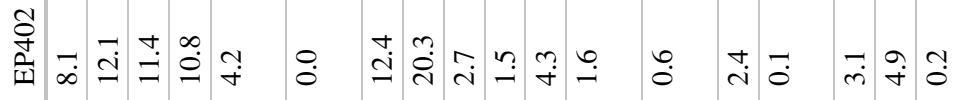
$\check{q}$

升

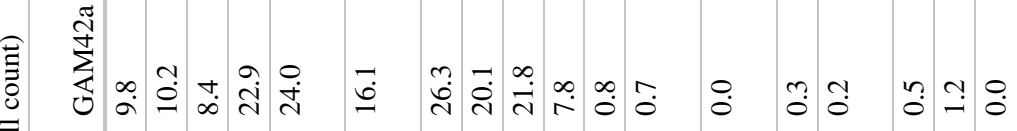
$\stackrel{\text { I }}{ \pm}$

踣 $\infty$

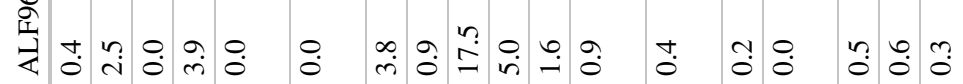
$\frac{n}{2}$

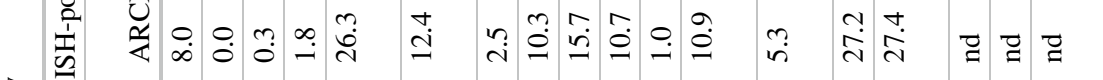

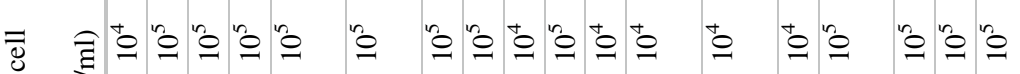

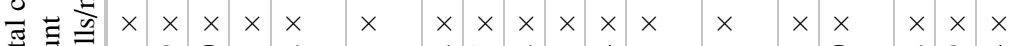

$\overline{\mathrm{s}} \cdot$

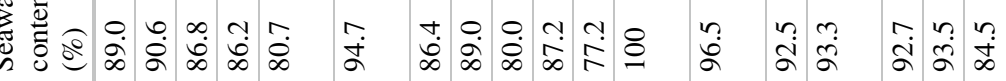

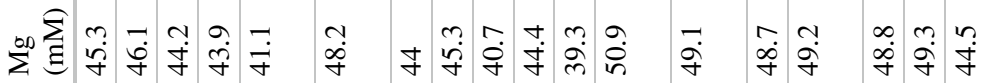

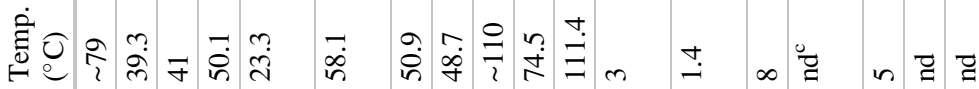
ปิ

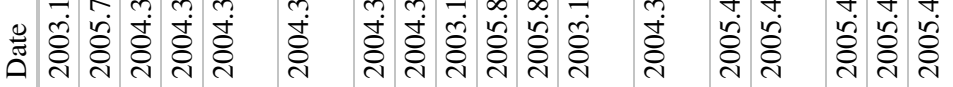

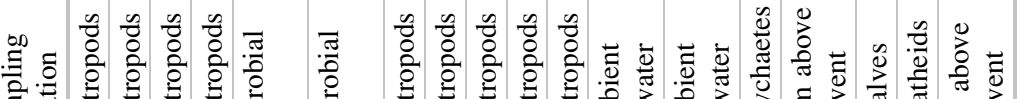

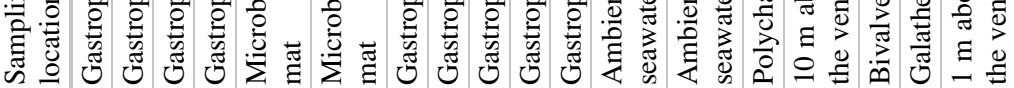
范

善言记

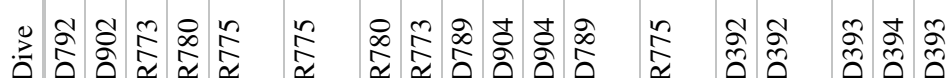

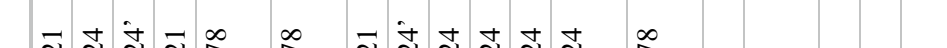

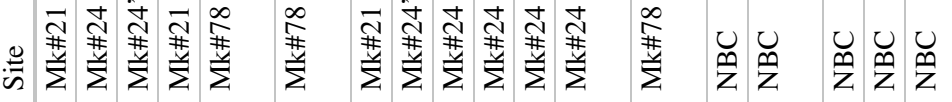

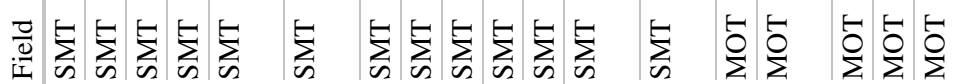


CARD-FISH was performed according to a previously published protocol (Pernthaler et al. 2002) with slight modifications, as described below. Microbial cells on polycarbonate filters were permeabilized with lysozyme $(10 \mathrm{mg} /$ $\mathrm{ml}$ in $0.05 \mathrm{M}$ EDTA and $0.1 \mathrm{M}$ Tris- $\mathrm{HCl}$ buffer [ $\mathrm{pH}$ 7.5]) for $70 \mathrm{~min}$ at $37^{\circ} \mathrm{C}$. The filters were then treated with $1 \% \mathrm{H}_{2} \mathrm{O}_{2}$ in methanol for $30 \mathrm{~min}$ at room temperature to deactivate the endogenous peroxidase. The microbial cells were then hybridized for $3 \mathrm{~h}$ at $35^{\circ} \mathrm{C}$ in hybridization buffer containing a horseradish peroxidase (HRP)-labeled oligonucleotide probe (final concentration: $5 \mathrm{pmol} / \mu \mathrm{l}$ ). The filter was then incubated in a washing buffer for $10 \mathrm{~min}$ at $37{ }^{\circ} \mathrm{C}$. The oligonucleotide probes, formamide concentrations in the hybridization buffer, and salt concentrations in the washing buffer are listed in Table 6.1. The filters were further washed with $0.05 \%$ TritonX-100 in $1 \times$ PBS (145 mM NaCl, $1.4 \mathrm{mM}$ $\mathrm{NaH}_{2} \mathrm{PO}_{4}, 8 \mathrm{mM} \mathrm{Na} \mathrm{HPO}_{4}$ [pH 7.4]) for $15 \mathrm{~min}$ at room temperature and then incubated in a 1:50 Cy3-labeled tyramide solution (TSA direct; PerkinElmer) for $10 \mathrm{~min}$ at $37{ }^{\circ} \mathrm{C}$ in the dark. The filter was then washed with $0.05 \%$ TritonX-100 in $1 \times$ PBS and dehydrated with ethanol. The microbial cells on each filter were stained with $1 \mu \mathrm{g} / \mathrm{ml}$ of 4',6-diamidino-2-phenylindole (DAPI). A ProLong Antifade Kit (Molecular Probes) was used to prevent photobleaching. To estimate the cell density, more than 1,000 cells in at least 25 microscopic fields were counted for each filter.

\subsubsection{Cluster Analysis of Microbial Community Composition by CARD-FISH}

A comparison of the microbial community structures was performed by cluster analysis using the web-based program Black Box (http://aoki2.si.gunma-u.ac.jp/index.html). A clustering algorithm based on the Ward method (Ward 1963) was applied to the bacterial community composition as determined by CARD-FISH using the oligonucleotide probes EUB338 I-III, ALF968, BET42a, GAM42a, DEL495, EP402, and CF319a. To reflect differences in the quantitative compositions of the microbial communities, none of the parameters were normalized.

\subsection{Results and Discussion}

\subsubsection{Quantitative Assessment of Microbial Community Composition by CARD-FISH}

The chemical composition of the hydrothermal fluid was strongly affected by the degree of dilution in the ambient seawater. Estimates based on $\mathrm{Mg}$ concentrations suggest that the fluid samples contained a large amount of seawater, ranging from 77.2 to $94.7 \%$ (Table 6.2). However, the microbial community composition of the hydrothermally influenced samples was significantly different from that of the ambient seawater. The CARD-FISH with specific oligonucleotide probes determined taxonomic composition and population size of prokaryotes inhabiting the hydrothermal vent environment. Up to $65.1 \%$ of the total cell count by DAPI staining hybridized with the bacteria-specific probes EUB338 I-III, while up to $27.4 \%$ of the total cell count hybridized with the archaea-specific probe ARCH915 (Table 6.2 and Fig. 6.1). Approximately one-half to onethird of the total cell count did not hybridize to either the bacteria- or archaea-specific probes and had smaller cell size than the other cells. Members of the Gammaproteobacteria were abundant in most of the samples from the SMT, accounting for more than half of the bacterial cells ( $26.3 \%$ of the total cell count). In contrast, the most abundant group in the fluid samples collected at the SMT in 2005 (D904RC3 and RC5) was Betaproteobacteria, which represented approximately $75 \%$ of the bacterial cell counts. Members of the Epsilonproteobacteria also constituted a significant fraction of the microbial cells in the SMT hydrothermal fluids, representing up to $20.3 \%$ of the total cell count. The Epsilonproteobacteria are widely distributed in deep-sea hydrothermal environments that are microaerophilic or anaerobic. The Epsilonproteobacteria include various chemolithoautotrophs that are capable of using hydrogen and sulfide as electron donors, and oxygen, nitrate, and elemental sulfur as electron acceptors (Campbell et al. 2006). At the SMT hydrothermal field, the Epsilonproteobacteria dominantly inhabited zones where the seawater content was between 86.2 and $90.6 \%$ (Fig. 6.2). Our findings suggest that these bacterial groups are not randomly distributed in the hydrothermal environments but have a preference for a specific ecological niche. The ALF968- and DEL495-positive cells were abundant in the D789RC2 and D780RC6 samples, respectively. However, relatively few of these cells were detected in the other samples. CF319a-positive cells had a very low detectability, accounting for less than $3.8 \%$ of most samples. In the samples from the MOT, most oligonucleotide probes identified very few cells, with the exception of SUP05187. The SUP05 group of sulfur oxidizers in Gammaproteobacteria was most abundant near vent fauna habitats in the MOT, as previously shown in the hydrothermal plume at the Suiyo Seamount (Sunamura et al. 2004). Sulfur oxidation would be one of the most feasible reactions in the hydrothermal environment of the MOT.

\subsubsection{Spatial and Temporal Variations in the Composition of the Bacterial Community}

While the 18 samples have different profiles in bacterial components, cluster analysis revealed that the bacterial 


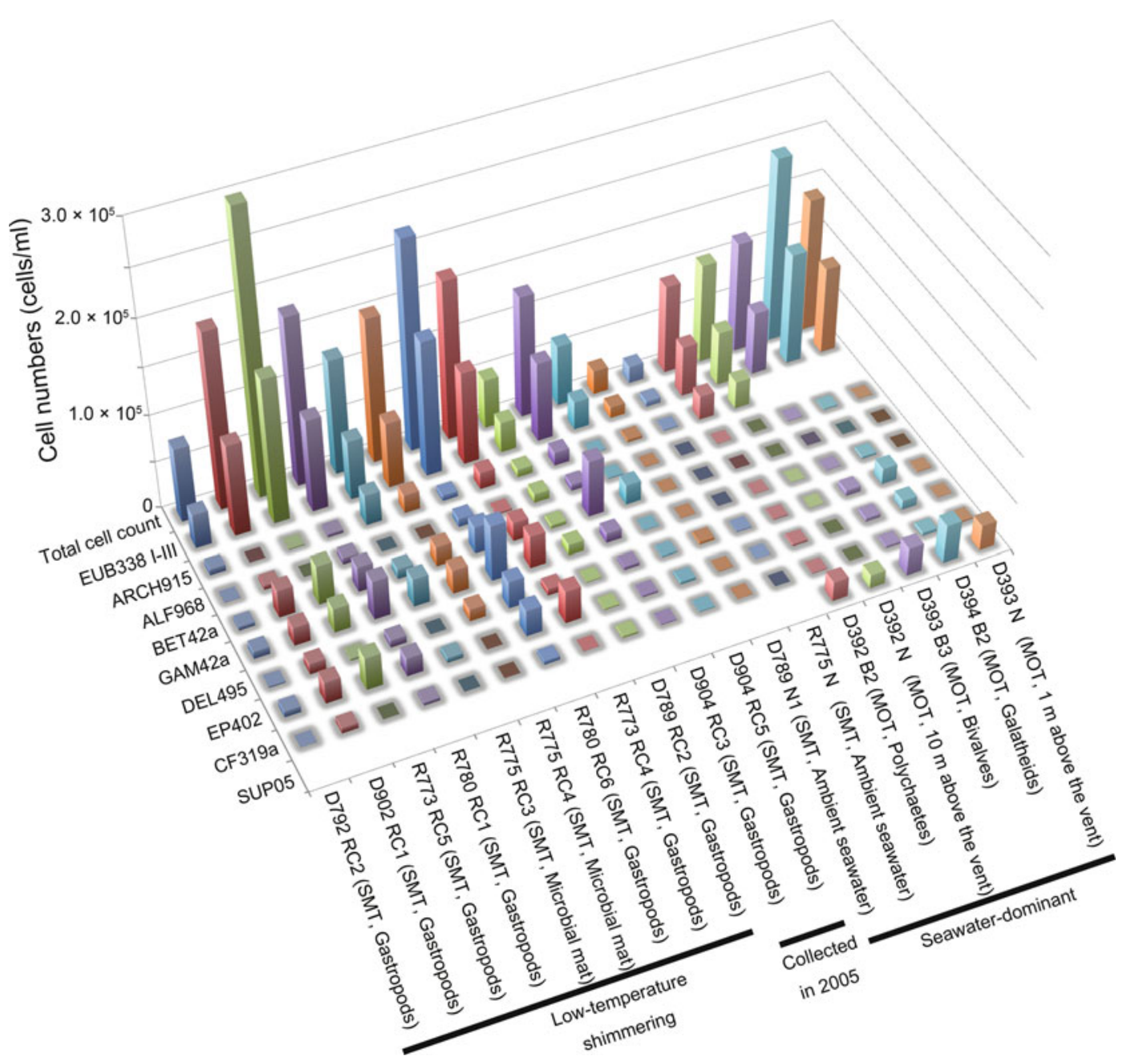

Fig. 6.1 Microbial community composition determined by CARD-FISH analysis

Fig. 6.2 The relative abundance of Epsilonproteobacteria in the mixed hydrothermal fluid and ambient seawater samples. The number of Epsilonproteobacteria cells was determined by CARDFISH using the EP402 probe. Solid circles, hydrothermal fluid samples from the Southern Mariana Trough (SMT); open circles, hydrothermal fluid samples from the Iheya North Knoll hydrothermal field of the Mid-Okinawa Trough (MOT)

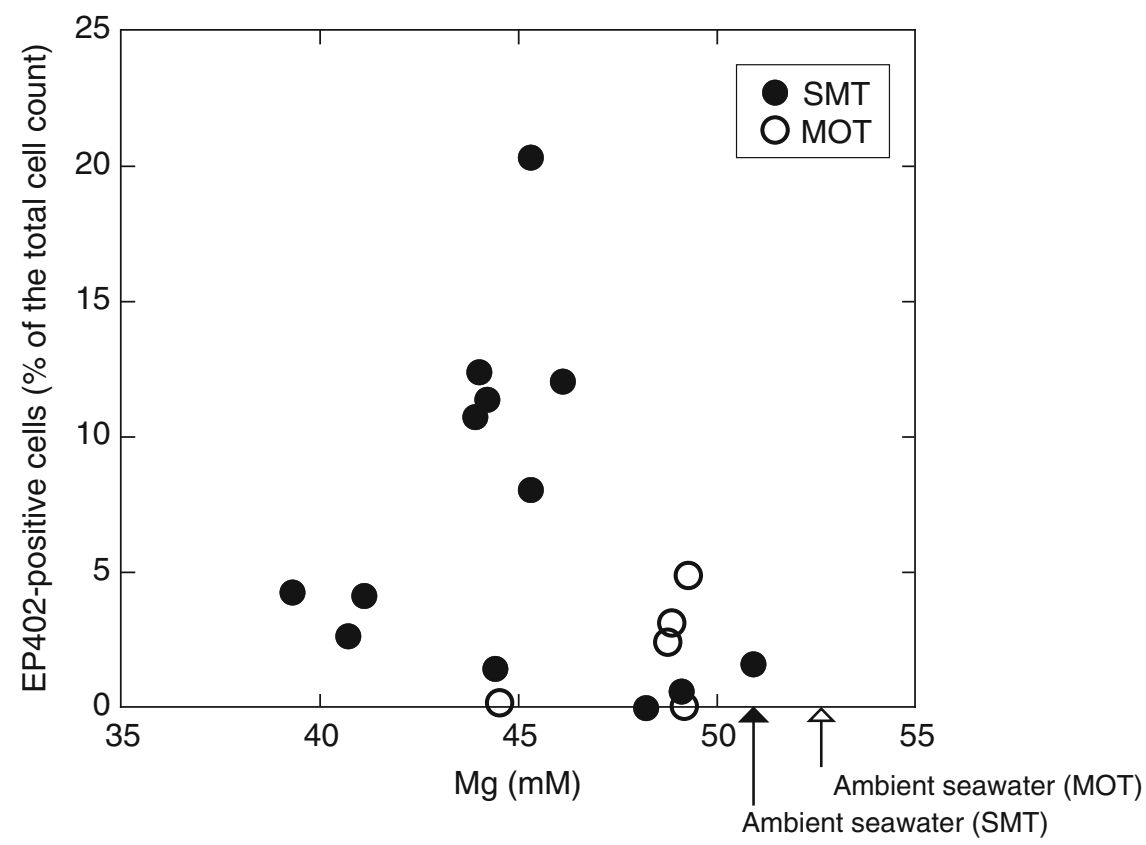




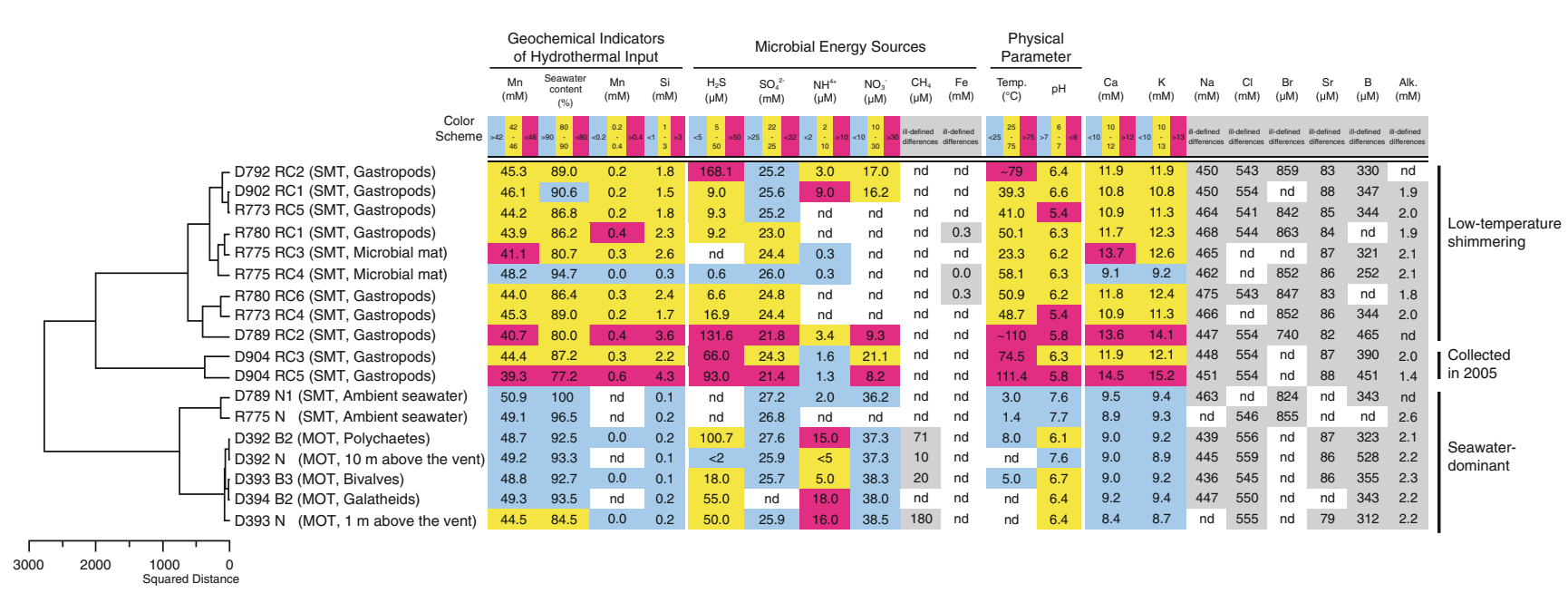

Fig. 6.3 Cluster analysis of the 18 bacterial communities and their environmental parameters in the deep-sea hydrothermal fluid and ambient seawater samples. The squared distance was calculated using the cell numbers as determined by CARD-FISH. The physical and

communities in the hydrothermal mixing zone formed a separate cluster from those in ambient seawater (Fig. 6.3). The chemical characteristics of the clusters suggest the following three distinguishable habitats conditions: (i) the seawaterdominant fluids composed of ambient seawater with a small portion of hydrothermal fluids, (ii) low-temperature shimmering, and (iii) the fluid samples collected at the SMT in 2005.

\subsubsection{Seawater-Dominant Fluids}

This cluster consisted of the ambient seawater samples and highly diluted hydrothermal fluids (Fig. 6.3). The average temperature during the sampling period ranged from 1.4 to $8.0{ }^{\circ} \mathrm{C}$, and the $\mathrm{Mg}$ concentration ranged from 44.5 to $50.9 \mathrm{mM}$, corresponding to seawater proportions ranging from 84.5 to $100 \%$. Total cell densities ranged from 1.8 to $19 \times 10^{4}$ cells $/ \mathrm{ml}$ (Table 6.2). CARD-FISH-positive cells for the probes of ALF968-, BET42a-, GAM42a-, DEL495-, EP402-, and CF319a were low in these samples (Table 6.2 and Fig. 6.1), possibly caused by the low expression of their ribosomal RNA or the dominance of other unidentified microbes.

\subsubsection{Low-Temperature Shimmering}

This cluster was composed of the samples from the SMT hydrothermal mixing zone (Fig. 6.3). The average temperature during the sampling period ranged from 23.3 to $110{ }^{\circ} \mathrm{C}$, and the $\mathrm{Mg}$ concentration ranged from 40.7 to $48.2 \mathrm{mM}$, corresponding to seawater proportions ranging from 80 to $94.7 \%$. Total cell densities ranged from 5.2 to $30 \times 10^{4}$ cells $/ \mathrm{ml}$ (Table 6.2). Though these shimmering fluid samples contained a substantial amount of seawater, the microbial community compositions in this cluster were notably different from the background seawater samples. The microbial chemical compositions of the hydrothermal fluids are color-coded to represent the degree of hydrothermal input in descending order from red to yellow to blue. Gray indicates samples that did not exhibit significant differences

communities were mainly composed of BET42a-, GAM42a, DEL495-, and EP402-positive cells (Table 6.2 and Fig. 6.1). A particularly high abundance of EP402-positive cells was detected in the sample of R773 RC4, comprising $20.3 \%$ of the total cell count. However, EP402-positive cells accounted for less than $5 \%$ of the total cell count in 12 of the 18 hydrothermal fluid samples (Fig. 6.2). The abundance of Epsilonproteobacteria in hydrothermal systems reported in previous studies is similar to the results found in this study (Nakagawa et al. 2006; Perner et al. 2007).

The microbial cell numbers were consistently high in the fluid samples from this cluster. Indeed, the total cell number in R773RC5 was 15-fold higher than in the ambient seawater samples (D789N1 and R775N). Furthermore, the microbial cells in the hydrothermal fluid samples were highly morphologically diverse, including rods, cocci, and filaments. A number of EP402-positive cells contained long filaments that were $3 \mu \mathrm{m}$ wide and $>100 \mu \mathrm{m}$ in length. In contrast, the microbial cells isolated from the ambient seawater samples were mainly small cocci. Because the filamentous EP402-positive cells exceeded the other cells in size, their biogeochemical impact on the hydrothermal ecosystem would be larger compared to an equal number of smaller cells. Future characterization of these filamentous populations is needed to address this issue.

The microbial community composition in this cluster most likely reflects the difference in fluid chemistry. The emanating hydrothermal fluids are mixed with and cooled by ambient seawater. The low-temperature shimmering is enriched with reduced inorganic compounds (electron donors) from hydrothermal fluid and oxidants (electron acceptors) derived from ambient seawater. Therefore, a physicochemical gradient produced from oxic/anoxic 
conditions and high/low temperatures around the hydrothermal vent may produce various habitat conditions to induce a phylogenetically, functionally, and morphologically diverse microbial community. The high proportion of Epsilonproteobacteria inhabiting oxygenated and low- to mediumtemperature environments has been reported in previous studies (Huber et al. 2003; Nakagawa et al. 2005).

\subsubsection{The Fluid Samples Collected at the SMT in 2005}

The samples collected during the YK05-09 cruise in 2005 clustered separately from the other SMT samples (Fig. 6.3). The average temperature during the sampling period ranged from 74.5 to $111.4{ }^{\circ} \mathrm{C}$, and the $\mathrm{Mg}$ concentration ranged from 39.3 to $44.4 \mathrm{mM}$, corresponding to seawater proportions ranging from 77.2 to $87.2 \%$ (Table 6.2). Total cell densities ranged from 6.4 to $13 \times 10^{4}$ cells $/ \mathrm{ml}$ (Table 6.2). This cluster was dominated by Betaproteobacteria, which accounted for $\sim 46.2 \%$ of the total cell count (Table 6.2 and Fig. 6.1). The dominance of Betaproteobacteria in habitats adjacent to gastropod aggregates may be supported by organic compounds excreted from gastropods, because heterotrophy is a dominant lifestyle in Betaproteobacteria. A similar temporal change in microbial community composition was previously observed in samples collected from the SMT borehole (Kato et al. 2009). This change may be due to long-term (yearscale) temporal fluctuation in the microbial community caused by a change in environmental factors.

\subsubsection{Hydrothermal Habitats for Microbial and Macrofaunal Communities}

Total cell densities ranged from 5.1 to $30 \times 10^{4}$ cells $/ \mathrm{ml}$ in the hydrothermal fluid samples to 1.8 to $4.2 \times 10^{4}$ cells $/ \mathrm{ml}$ in the ambient seawater samples (Table 6.2). Hence, the microbial cell abundance at the SMT was two- to ten-fold higher than in ambient seawater. In contrast, the total cell number in the hydrothermal fluid in the MOT was only twice that in the seawater samples. These data clearly indicate that the microbial community relies on hydrothermal energy input to the deep-sea where energy sources are typically scarce, and they reveal the regional variation and temporal fluctuation.

The stability of the hydrothermal activity is a primary factor to sustain the microbial and macrofaunal communities. The hydrothermal vents in the SMT are estimated to be stable over several years with regard to temperature and geochemical composition (Toki et al. Chap. 45). In contrast, the hightemperature venting activity in the MOT may create fluctuating habitats for both microorganisms and macrofauna due to vigorous mixing conditions.

\subsection{Conclusions}

In this study, we used a CARD-FISH-based quantitative approach to demonstrate that the microbial community composition of the SMT hydrothermal field is distinct from that of the MOT hydrothermal field. The SMT mixing zone harbored phylogenetically and morphologically diverse and abundant microbial populations compared to seawaterdominant samples. Although it was not possible to obtain data on the metabolism of microbial species detected by CARD-FISH (i.e., whether they were chemolitho-, mixoor heterotrophic), the microbial community may include heterotrophs such as Alphaproteobacteria, Betaproteobacteria, and Cytophaga-Flavobacterium clusters. This finding may indicate that hydrothermal fluid components have an indirect impact on heterotrophic microbial populations. If so, future investigations should focus on the food web within the macrofaunal community. Our quantitative data will help predict the contribution of microbes to biogeochemical processes in deep-sea hydrothermal environments. Further research is needed to gain a better understanding of the functional role and biogeochemical impact of hydrothermal vent microorganisms.

Acknowledgements We are deeply grateful to the crews of the R/V Thomas G. Thompson, the R/V Yokosuka, and the R/V Natsushima and the operation teams of the ROV ROPOS, Shinkai 6500, and HyperDolphin during the YK03-09, YK05-09, TN167A, and NT05-03 cruises. We also thank the shipboard science parties for the cruises and the members of the project TAIGA and Archaean Park for providing us with valuable samples and for helpful discussions. This work was supported in part by the Grant-in-Aid for Scientific Research: Project TAIGA (New Scientific Research on Innovative Areas, 20109003) and the Archaean Park Project (International Research Project on Interaction between Sub-Vent Biosphere and Geo-Environments).

Open Access This chapter is distributed under the terms of the Creative Commons Attribution Noncommercial License, which permits any noncommercial use, distribution, and reproduction in any medium, provided the original author(s) and source are credited.

\section{References}

Amann RI, Ludwig W, Schleifer KH (1995) Phylogenetic identification and in situ detection of individual microbial cells without cultivation. Microbiol Rev 59(1):143-169

Campbell BJ, Engel AS, Porter ML, Takai K (2006) The versatile $\varepsilon$-proteobacteria: key players in sulphidic habitats. Nat Rev Microbiol 4(6):458-468

Corliss JB et al (1979) Submarine thermal springs on the Galápagos Rift. Science 203(4385):1073-1083

Daims H, Brühl A, Amann R, Schleifer K-H, Wagner M (1999) The domain-specific probe EUB338 is insufficient for the detection of all bacteria: development and evaluation of a more comprehensive probe set. Syst Appl Microbiol 22(3):434-444 
Flores GE, Shakya M, Meneghin J, Yang ZK, Seewald JS, Geoff Wheat C, Podar M, Reysenbach AL (2012) Inter-field variability in the microbial communities of hydrothermal vent deposits from a backarc basin. Geobiology 10(4):333-346

Gieskes JM, Gamo T, Brumsack H (1991) Chemical methods for interstitial water analysis aboard Joides Resolution. Ocean Drilling Program Technical Note 15

Holden JF, Summit M, Baross JA (1998) Thermophilic and hyperthermophilic microorganisms in $3-30^{\circ} \mathrm{C}$ hydrothermal fluids following a deep-sea volcanic eruption. FEMS Microbiol Ecol 25 (1):33-41

Huber JA, Butterfield DA, Baross JA (2002) Temporal changes in archaeal diversity and chemistry in a mid-ocean ridge subseafloor habitat. Appl Environ Microbiol 68(4):1585-1594

Huber JA, Butterfield DA, Baross JA (2003) Bacterial diversity in a subseafloor habitat following a deep-sea volcanic eruption. FEMS Microbiol Ecol 43(3):393-409

Huber JA, Cantin HV, Huse SM, Mark Welch DB, Sogin ML, Butterfield DA (2010) Isolated communities of Epsilonproteobacteria in hydrothermal vent fluids of the Mariana Arc seamounts. FEMS Microbiol Ecol 73(3):538-549

Karl DM (1995) Ecology of free-living, hydrothermal vent microbial communities. In: Karl DM (ed) The microbiology of deep-sea hydrothermal vents. CRC, Boca Raton, pp 35-124

Kato $S$ et al (2009) Abundance of Zetaproteobacteria within crustal fluids in back-arc hydrothermal fields of the Southern Mariana Trough. Environ Microbiol 11(12):3210-3222

Le Bris N, Govenar B, Le Gall C, Fisher CR (2006) Variability of physico-chemical conditions in $9^{\circ} 50^{\prime} \mathrm{N}$ EPR diffuse flow vent habitats. Mar Chem 98(2-4):167-182

Loy A, Lehner A, Lee N, Adamczyk J, Meier H, Ernst J, Schleifer K-H, Wagner M (2002) Oligonucleotide microarray for $16 \mathrm{~S}$ rRNA genebased detection of all recognized lineages of sulfate-reducing prokaryotes in the environment. Appl Environ Microbiol 68 (10):5064-5081

Manz W, Amann R, Ludwig W, Wagner M, Schleifer K-H (1992) Phylogenetic oligodeoxynucleotide probes for the major subclasses of proteobacteria: problems and solutions. Syst Appl Microbiol 15 (4):593-600

Manz W, Amann R, Ludwig W, Vancanneyt M, Schleifer K-H (1996) Application of a suite of $16 \mathrm{~S}$ rRNA-specific oligonucleotide probes designed to investigate bacteria of the phylum cytophagaflavobacter-bacteroides in the natural environment. Microbiology 142(5):1097-1106

Maruo M, Doi T, Obata H (2006) Anion chromatographic determination of submicromolar nitrate in seawater with a high-capacity anion exchanger and lithium chloride eluent on shipboard. Anal Sci 22:1175-1178

Nakagawa S, Takai K, Inagaki F, Chiba H, Ishibashi J, Kataoka S, Hirayama H, Nunoura T, Horikoshi K, Sako Y (2005) Variability in microbial community and venting chemistry in a sediment-hosted backarc hydrothermal system: impacts of subseafloor phaseseparation. FEMS Microbiol Ecol 54(1):141-155

Nakagawa T, Takai K, Suzuki Y, Hirayama H, Konno U, Tsunogai U, Horikoshi K (2006) Geomicrobiological exploration and characterization of a novel deep-sea hydrothermal system at the TOTO caldera in the Mariana Volcanic Arc. Environ Microbiol 8 (1):37-49
Neef A (1997) Anwendung der in situ Einzelzell-Identifizierung von Bakterien zur Populationsanalyse in komplexen mikrobiellen Biozönosen. Doctoral thesis (Technische Universität München)

Nunoura T, Takai K (2009) Comparison of microbial communities associated with phase-separation-induced hydrothermal fluids at the Yonaguni Knoll IV hydrothermal field, the Southern Okinawa Trough. FEMS Microbiol Ecol 67(3):351-370

Nunoura $\mathrm{T}$ et al (2010) Archaeal diversity and distribution along thermal and geochemical gradients in hydrothermal sediments at the Yonaguni Knoll IV hydrothermal field in the southern Okinawa Trough. Appl Environ Microbiol 76(4):1198-1211

Perner M, Seifert R, Weber S, Koschinsky A, Schmidt K, Strauss H, Peters M, Haase K, Imhoff JF (2007) Microbial $\mathrm{CO}_{2}$ fixation and sulfur cycling associated with low-temperature emissions at the Lilliput hydrothermal field, southern Mid-Atlantic Ridge $\left(9^{\circ} \mathrm{S}\right)$. Environ Microbiol 9(5):1186-1201

Perner M, Bach W, Hentscher M, Koschinsky A, Garbe-Schönberg D, Streit WR, Strauss H (2009) Short-term microbial and physicochemical variability in low-temperature hydrothermal fluids near $5^{\circ} \mathrm{S}$ on the Mid-Atlantic Ridge. Environ Microbiol 11(10):2526-2541

Perner M, Gonnella G, Hourdez S, Böhnke S, Kurtz S, Girguis P (2013) In situ chemistry and microbial community compositions in five deep-sea hydrothermal fluid samples from Irina II in the Logatchev field. Environ Microbiol 15(5):1551-1560

Pernthaler A, Pernthaler J, Amann R (2002) Fluorescence in situ hybridization and catalyzed reporter deposition for the identification of marine bacteria. Appl Environ Microbiol 68(6):3094-3101

Rogers KL, Amend JP, Gurrieri S (2007) Temporal changes in fluid chemistry and energy profiles in the vulcano island hydrothermal system. Astrobiology 7(6):905-932

Schrenk MO, Kelley DS, Delaney JR, Baross JA (2003) Incidence and diversity of microorganisms within the walls of an active deep-sea sulfide chimney. Appl Environ Microbiol 69(6):3580-3592

Sunamura M, Higashi Y, Miyako C, Ishibashi J, Maruyama A (2004) Two bacteria phylotypes are predominant in the Suiyo Seamount hydrothermal plume. Appl Environ Microbiol 70(2):1190-1198

Takai K, Komatsu T, Inagaki F, Horikoshi K (2001) Distribution of archaea in a black smoker chimney structure. Appl Environ Microbiol 67(8):3618-3629

Takai K, Oida H, Suzuki Y, Hirayama H, Nakagawa S, Nunoura T, Inagaki F, Nealson KH, Horikoshi K (2004) Spatial distribution of marine crenarchaeota group I in the vicinity of deep-sea hydrothermal systems. Appl Environ Microbiol 70(4):2404-2413

Teske A, Hinrichs K-U, Edgcomb V, de Vera Gomez A, Kysela D, Sylva SP, Sogin ML, Jannasch HW (2002) Microbial diversity of hydrothermal sediments in the Guaymas Basin: evidence for anaerobic methanotrophic communities. Appl Environ Microbiol 68 (4):1994-2007

Ward JH (1963) Hierarchical grouping to optimize an objective function. J Am Stat Assoc 58(301):236-244

Yanagawa $\mathrm{K}$ et al (2013) Metabolically active microbial communities in marine sediment under high- $\mathrm{CO}_{2}$ and low-pH extremes. ISME $\mathrm{J}$ 7:555-567

Zielinski FU, Gennerich H-H, Borowski C, Wenzhöfer F, Dubilier N (2011) In situ measurements of hydrogen sulfide, oxygen, and temperature in diffuse fluids of an ultramafic-hosted hydrothermal vent field (Logatchev, $14^{\circ} 45^{\prime} \mathrm{N}$, Mid-Atlantic Ridge): implications for chemosymbiotic bathymodiolin mussels. G Cubed 12(9):Q0AE04 